\title{
Elevated albumin-to-creatinine ratio as a risk factor for stroke and homocysteine as an effect modifier in hypertensive Asian individuals
}

\author{
Michihiro Satoh ${ }^{1,2}$
}

Received: 6 October 2021 / Accepted: 12 October 2021 / Published online: 5 November 2021

(c) The Japanese Society of Hypertension 2021

The global lifetime risk of stroke in 2016 was estimated to be approximately $25 \%$ [1]. The risk was higher in Southeast Asia, East Asia, and Oceania than in other regions [1]. Albuminuria has emerged as an important risk factor for cardiovascular diseases, including stroke. A previous meta-analysis indicated that, independent of the estimated glomerular filtration rate (eGFR), a $25-\mathrm{mg} / \mathrm{mmol}$ increase in the albumin-to-creatinine ratio (ACR) was associated with a $10 \%$ increased risk of stroke [2]. However, information on the association of ACR with the risk of stroke in Asia and effect modifiers in this association has been limited.

He et al. investigated the ACR and the risk of first stroke in hypertensive Chinese patients treated with angiotensinconverting enzyme inhibitors (ACEIs) using China Stroke Primary Prevention Trial (CSPPT) data [3]. The CSPPT was a multicommunity, randomized, double-blind clinical trial that evaluated the effectiveness of enalapril plus folic acid therapy compared with enalapril alone for reducing the risk of first stroke. Figure 1 is the summary of their findings [3]. Patients with ACR $\geq 10 \mathrm{mg} / \mathrm{g}$ had a 1.5 times higher risk of stroke than those with ACR $<10 \mathrm{mg} / \mathrm{g}$ [3]. A high ACR was apparently more strongly associated with ischemic stroke than with hemorrhagic stroke [3]. In the CSPPT, the eligible participants were hypertensive patients aged 45-75 years without a history of physician-diagnosed stroke, myocardial infarction, heart failure, coronary revascularization, or congenital heart disease [4]. The average eGFR was over $70 \mathrm{~mL} / \mathrm{min} / 1.73 \mathrm{~m}^{2}$ in all groups categorized according to ACR category. Therefore, their findings can be

Michihiro Satoh

satoh.mchr@gmail.com

1 Division of Public Health, Hygiene and Epidemiology, Faculty of Medicine, Tohoku Medical and Pharmaceutical University, Sendai, Japan

2 Department of Preventive Medicine and Epidemiology, Tohoku Medical Megabank Organization, Tohoku University, Sendai, Japan generalizable to hypertensive populations with fewer complications and can be broadly applicable in primary care [3]. Notably, in their study, hypertensive patients had been treated with ACEIs during the follow-up period [3]. Reninangiotensin inhibitors decrease albuminuria [5-7]. Albuminuria at baseline or increased albuminuria following antihypertensive treatment initiation is a risk factor for endstage renal disease, cardiovascular risk, and all-cause mortality [5-8]. The present findings suggest that ACR levels could be a risk factor for stroke even in Asians treated with renin-angiotensin inhibitors [3].

Their study also suggested that elevated total plasma homocysteine $([\mathrm{t}] \mathrm{Hcy})$ would be an effect modifier in the association between high ACR and increased stroke risk. A recent study demonstrated a significant interaction between hypertension and tHcy levels and the risk of all-cause and cardiovascular disease mortality [9]. Hcy is a sulfur-containing amino acid formed as a byproduct of methyl-transfer reactions in methionine metabolism. As mentioned in their discussion [3], increased tHcy can promote atherosclerosis by inhibiting endothelial cell growth, promoting thrombosis, and increasing oxidative stress. A previous study using a mediation analysis suggested that tHcy can accelerate atherosclerosis partly via renal impairment [10], which may support the present findings from the CSPPT data. In the report by He et al., the stroke risk in the $\mathrm{ACR} \geq 10 \mathrm{mg} / \mathrm{g}$ with tHcy $\geq 10 \mu \mathrm{mol} / \mathrm{L}$ group was 1.74 times higher than that in the highest $\mathrm{ACR}<10 \mathrm{mg} / \mathrm{g}$ with tHcy $<10 \mu \mathrm{mol} / \mathrm{L}$ group [3]. However, this significant association was diminished after adjustments for various baseline characteristics, including albumin, carotid intimamedia thickness, and eGFR (Table S3 in their report) [3]. Further studies, such as those utilizing mediation analysis, may be needed to clarify the detailed pathway of the deleterious effect of high ACR combined with high tHcy.

Folic acid and vitamins play important roles in tHcy levels. A meta-analysis suggested that Hcy-lowering interventions in the form of vitamin $\mathrm{B}_{6}, \mathrm{~B}_{9}$, or $\mathrm{B}_{12}$ supplementation alone or in combination, compared with a placebo, lowered the risk of stroke [11]. The primary analysis of the CSPPT data 


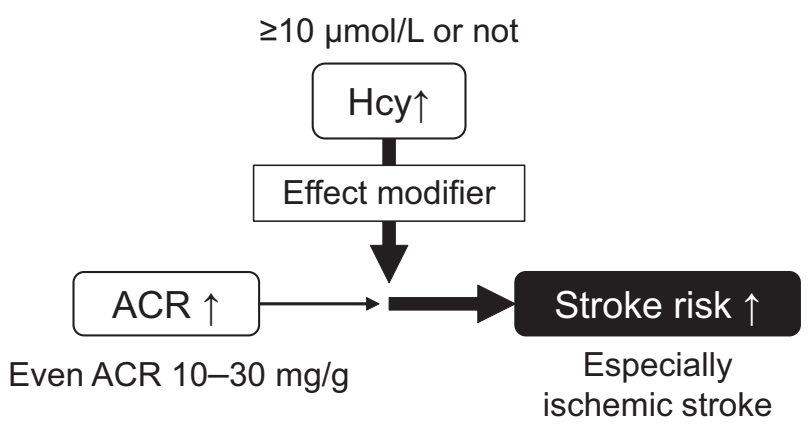

Fig. 1 The role of homocysteine (Hcy) in the association between the albumin-to-creatinine ratio (ACR) and stroke risk

demonstrated that the combined use of enalapril and folic acid, compared with enalapril alone, significantly reduced the risk of first stroke [4]. Therefore, it was expected that folic supplementation can also weaken the association between ACR and first stroke risk. The slight reduction in the hazard ratio of stroke for $\mathrm{ACR} \geq 10 \mathrm{mg} / \mathrm{g}$ in the folic supplementation group compared with that in the nonsupplementation group [3] may imply that folic supplementation can attenuate the adverse effect of high ACR enhanced by hyperhomocysteinemia. However, no significant interaction between folic supplementation and ACR on the risk of first stroke was observed [3]. This implies that other treatments or actions should be considered to weaken the positive association between ACR and the risk of stroke. We should also consider the possibility that other factors elevating tHcy, such as nutrients, can be true effect modifiers.

The significant interaction between tHcy and ACR also implies that elevated ACR can be an effect modifier in the association between tHcy and stroke risk. Studies assessing the effects of tHcy should consider ACR levels. Furthermore, it is also suggested that preventing ACR elevation can reduce the adverse effects of tHcy. The impact of chronic kidney disease on lifetime stroke risk was found to be similar to that of hypertension in Asian populations [12]. Albuminuria should be assessed regularly from the viewpoint of stroke prevention, even in Asians without any overt kidney diseases.

\section{Compliance with ethical standard}

Conflict of interest The author declares no competing interests.
Publisher's note Springer Nature remains neutral with regard to jurisdictional claims in published maps and institutional affiliations.

\section{References}

1. Collaborators GBDLRoS, Feigin VL, Nguyen G, Cercy K, Johnson CO, Alam T, et al. Global, regional, and country-specific lifetime risks of stroke, 1990 and 2016. N. Engl J Med. 2018;379: 2429-37.

2. Masson P, Webster AC, Hong M, Turner R, Lindley RI, Craig JC. Chronic kidney disease and the risk of stroke: a systematic review and meta-analysis. Nephrol Dial Transpl. 2015;30:1162-9.

3. He P, Yang Y, Tian J, Yang M, Lin Z, Li H, et al. Urinary albumin to creatinine ratio and the risk of first stroke in Chinese hypertensive patients treated with angiotensin-converting enzyme inhibitors. Hypertens Res. 2021. https://doi.org/10.1038/s41440021-00780-5. E-pub ahead of print.

4. Huo Y, Li J, Qin X, Huang Y, Wang X, Gottesman RF, et al. Efficacy of folic acid therapy in primary prevention of stroke among adults with hypertension in China: the CSPPT randomized clinical trial. JAMA. 2015;313:1325-35.

5. Heerspink HJ, Ninomiya T, Persson F, Brenner BM, Brunel $\mathrm{P}$, Chaturvedi $\mathrm{N}$, et al. Is a reduction in albuminuria associated with renal and cardiovascular protection? A post hoc analysis of the ALTITUDE trial. Diabetes Obes Metab. 2016;18:169-77.

6. de Zeeuw D, Remuzzi G, Parving HH, Keane WF, Zhang Z, Shahinfar S, et al. Proteinuria, a target for renoprotection in patients with type 2 diabetic nephropathy: lessons from RENAAL. Kidney Int. 2004;65:2309-20.

7. Jun M, Ohkuma T, Zoungas S, Colagiuri S, Mancia G, Marre M, et al. Changes in albuminuria and the risk of major clinical outcomes in diabetes: results from ADVANCE-ON. Diabetes Care. 2018;41:163-70.

8. Ninomiya T, Perkovic V, de Galan BE, Zoungas S, Pillai A, Jardine M, et al. Albuminuria and kidney function independently predict cardiovascular and renal outcomes in diabetes. J Am Soc Nephrol. 2009;20:1813-21.

9. Zhao W, Gao F, Lv L, Chen X. The interaction of hypertension and homocysteine increases the risk of mortality among middle-aged and older population in the United States. J Hypertens. 2021. https://doi. org/10.1097/HJH.0000000000003002. E-pub ahead of print.

10. Spence JD, Urquhart BL, Bang H. Effect of renal impairment on atherosclerosis: only partially mediated by homocysteine. Nephrol Dial Transpl. 2016;31:937-44.

11. Marti-Carvajal AJ, Sola I, Lathyris D, Dayer M. Homocysteinelowering interventions for preventing cardiovascular events. Cochrane Database Syst Rev. 2017;8:CD006612.

12. Nakayama S, Satoh M, Metoki H, Murakami T, Asayama K, Hara A, et al. Lifetime risk of stroke stratified by chronic kidney disease and hypertension in the general Asian population: the Ohasama study. Hypertens Res. 2021. 